\title{
¿Tiene el Derecho del Trabajo alguna respuesta ante la prostitución?
}

\section{Does labour law have any responses to prostitution?}

\author{
Carolina Martínez Moreno \\ ORCID ID: 0000-0001-5316-3637
}

doi: https://doi.org/10.20318/labos.2020.5544

\section{Algunas consideraciones preliminares}

El enfoque tradicional de la prostitución -intercambio de sexo por dinero- desde el ordenamiento laboral ha consistido en negar la posibilidad de considerar dicha actividad como parte integrante del objeto o campo de aplicación de aquel al tratarse de una actividad ilícita y contraria a la moral, no susceptible de instrumentar a través de un contrato (arts.1.271 y 1.275 CC), el de trabajo en este caso. Más modernamente, situar a los derechos básicos de la persona en el centro del debate, atribuir a la dignidad humana y a la libertad individual la condición o cualidad de valores superiores de nuestro ordenamiento y pilares básicos de la convivencia, conduciría o reforzaría aún más dicho presupuesto.

Sin embargo, y siempre desde un punto de vista estrictamente personal, esta no deja de ser una visión un tanto simplista del asunto, por varias razones. La primera, que el hecho de que el ordenamiento general no se integre de compartimentos estancos implica que el Derecho del Trabajo y las instituciones que el mismo comprende pueden entrar en relación e interactuar con otras ramas del ordenamiento, en particular con el Derecho Internacional y el Derecho Penal, centrados en la protección de las víctimas de trata de seres humanos o de explotación. De hecho, con frecuencia este tipo de situaciones se detectan gracias a la estrecha colaboración entre las Fuerzas y Cuerpos de Seguridad del Estado y la Inspección de Trabajo y Seguridad Social, en ejercicio esta última de sus atribuciones para perseguir y que se sancionen conductas vulneradoras y lesivas de los derechos de los trabajadores, situaciones de fraude laboral, o infracciones en materia de trabajo de ciudadanos extranjeros o menores de edad. De este modo el Derecho del Trabajo irrumpe de lleno en la realidad económica y en el contexto social en los que se desenvuelve la prostitución.

La segunda razón por la que creo que no se puede sostener que el que podría denominarse "mercado del sexo" sea algo ajeno por completo a la normativa laboral es que dentro del mismo quedan englobadas actividades y servicios de muy variada índole -desde la lúdica, de ocio y esparcimiento, a la menos conocida de tipo asistencial-, respecto de cuya licitud o posibilidad legal no se ha suscitado duda alguna hasta este momento. Al contrario, alrededor del sexo se articulan y organizan actividades económicas que incluso pueden llegar a ser muy lucrativas, como la pornografía,

"cmmoreno@uniovi.es 
en sus variadas expresiones y soportes; las líneas eróticas; las saunas y casas de masajes; los servicios de escort -azafatas, modelos o acompañantes-; los clubes de estreaptease o de lap dance; y hasta la llamada "asistencia sexual" para las personas con limitaciones funcionales que dificulten la práctica espontánea y autónoma del sexo. Y, naturalmente, el "alterne” y la prostitución. Actividades y negocios con mucha frecuencia entremezclados, y que pueden servir -lo hacen, de hecho- para enmascarar y proporcionar un paraguas de legalidad al ejercicio de la prostitución. Esto es particularmente visible, al menos desde la perspectiva jurídico-laboral, en relación con el alterne, que es respecto del que existe más casuística, más claros criterios administrativos y más abundante doctrina judicial.

Por otra parte, la dignidad humana y la libertad personal admiten una comprensión y un entendimiento en un doble sentido que no deja de encubrir -o puede hacerlo- un prejuicio ideológico o un posicionamiento moral. Por un lado, como obstáculos insalvables para admitir la prostitución, para negar a las personas que la ejercen la capacidad de discernimiento para decidir su propia vida; pero también para justamente lo contrario, para fundar la posibilidad de una disposición libre y autónoma del propio cuerpo y de la sexualidad sin que el resultado tenga inexorablemente que ser el de la reprobación social y la estigmatización.

Sea como fuere, la realidad, incluso la regulada, va por otros derroteros. Y la anomia o la ambigüedad, cuando no la incongruencia y la contradicción normativas, habilitan espacios para que la prostitución no sólo sea un fenómeno posible, sino un negocio tremendamente lucrativo para una de las partes, y sin derechos para la que ocupan las personas de las que se nutre.

\section{Una panorámica del negocio del sexo desde la normativa internacional y europea}

La primera y principal norma laboral internacional que se ocupa de la prostitución es el Convenio sobre el trabajo forzoso de la OIT de 1930 (Protocolo adoptado en la 103a reunión en Ginebra en 2014), que la prohíbe como trabajo por cuenta ajena, aunque nada dice sobre si podría constituir un trabajo por cuenta propia.

Por su parte, el Derecho de la Unión Europea adopta, como ya se ha dicho, una visión "victimocéntrica" (C. VILLACAMPA ESTIARTE), conforme a la cual se establece una correspondencia estricta entre prostitución y trata de seres humanos [Resolución del Parlamento Europeo sobre la situación actual en la lucha contra la violencia ejercida contra las mujeres y futuras acciones de 2006 (http://www.europarl.europa.eu/sides/getDoc.do?pubRef=-//EP//TEXT+TA+P6-TA-2006$0038+0+\mathrm{DOC}+\mathrm{XML}+\mathrm{V} 0 / / \mathrm{ES})$. La prostitución se concibe además como una práctica contraria a la igualdad de género, por definición incompatible con la consideración como un "trabajo" $[R e-$ comendación sobre explotación sexual y prostitución y su impacto en la igualdad de género, de 23 de febrero de 2014 (http://www.europarl.europa.eu/sides/getDoc.do?pubRef=-//EP//TEXT+TA+P7TA-2014-0162+0+DOC+XML+V0//ES)]; y, en concordancia con ello, se propugna la ilegalización del proxenetismo y la instauración de un modelo como el nórdico que penalice la compra de servicios sexuales [Directiva 2011/36/UE, del Parlamento y del Consejo, de 5 de abril de 2011, relativa a la prevención y lucha contra la trata de seres humanos y a la protección de las victimas (http://eur-lex. europa.eu/LexUriServ/LexUriServ.do?uri=OJ:L:2011:101:0001:0011:Es:PDF)].

Pese a todo, la situación en Europa no es ni mucho menos así de clara y terminante, ya que el TJUE ha admitido en ocasiones que la prostitución pueda ser una profesión o fuente de ingresos lícita. Indirectamente lo hace la STJUE de 16 de noviembre de 2004, asunto Panayotova (C-327/02) [ECLI:EU:C:2004:718]. Pero, con mayor claridad, la STJUE (Pleno) de 20 de noviembre de 2001, asunto Jany y otras (C-268/99) [ECLI:EU:C:2001:616], a propósito de la libertad de establecimiento, y en el marco de los Acuerdos de Asociación con las Repúblicas de Polonia y Chequia, considera 
que la prostitución forma parte de las actividades económicas ejercidas de manera independiente a las que se refieren las disposiciones de dichos Acuerdos, siempre y cuando se demuestre "que el prestador del servicio la ejerce sin vínculo de subordinación por lo que respecta a la elección de dicha actividad (y) a las condiciones de trabajo y de retribución; bajo responsabilidad propia, y a cambio de una remuneración que se le paga íntegra y directamente.” Algo más tarde, la STJUE de 16 de diciembre de 2010, asunto Josemans (C-137/09) [ECLI:EU:C:2010:774], en referencia a la posibilidad de limitar la admisión a los coffee shops de los no residentes en los Países Bajos, vuelve a echar mano de la sentencia Jeny para afirmar que "...la prostitución, exceptuando la trata de seres humanos, no está prohibida por el Derecho internacional o por el de la Unión (sino que)... En efecto, se tolera o regula en varios Estados miembros." Y, en fin, más recientemente, la STJUE de 8 de mayo de 2019, asunto PI (C-230/18) [ECLI:EU:C:2019:383], reitera que la libertad de establecimiento y libre prestación de servicios se oponen a una normativa nacional (la austriaca) que permite que una autoridad administrativa pueda decidir el cierre inmediato de un establecimiento comercial, sin comunicar los motivos al titular. En el caso, se trataba de un centro de masajes explotado en Austria por una nacional búlgara donde se sospechaba que se ejercía la prostitución (la cuestión procede del Tribunal Regional de lo contencioso-administrativo del Tirol) [http://curia.europa.eu/juris/document/document.jsf?docid= 213853\&mode=req\&pageIndex=2\&dir=\&occ=first\&part=1\&text=\&doclang=ES\&cid=2177644] .

La complejidad y las contradicciones provienen en buena medida de la diversidad de sistemas y modelos de regulación adoptados por los distintos países de la UE, que van desde el abolicionismo y la prohibición, a la legalización -restrictiva y protectora-, pasando por la mera tolerancia o anomia (P. RIVAS VALLEJO). Con variantes, a su vez, en el modo de concreción del sentido y la intensidad de las regulaciones: prohibición de cualquier actividad o negocio relacionado con el sexo; admisión de la licitud del resto de servicios sexuales distintos a la prostitución (modelo neoabolicionista nórdico); admisión de la prostitución ejercida por cuenta propia [con aplicación de las normas tributarias (STEDH de 11 de septiembre de 2007, asunto Tremblay contra Francia)]; legalización limitativa y garante de derechos como ocurre en Austria o Alemania (F. ALEMÁN PÁEZ). A todo lo cual se suman los llamados sistemas "redencionistas", en los que se trata de propiciar el abandono de la actividad y la reintegración laboral de esas personas en otros oficios y profesiones, en la idea de que la prostitución se ejerce casi siempre bajo la compulsión de la necesidad económica, factor que, sin embargo, y como es bien sabido, concurre en una buena parte de los empleos.

Lo que aquí se pretende es transmitir y compartir la sensación de que esa dicotomía entre la regulación entendida como legalización y la proscripción y el apartamiento del fenómeno del ámbito del Derecho del Trabajo (S. OLARTE ENCABO; y J.F. LOUSADA AROCHENA), por desgracia no garantiza, en el caso de lo segundo, que las personas que ejercen la prostitución queden preservadas frente a la precariedad, la estigmatización social y la marginalidad. Más bien parece que ocurre lo contrario. Y que, en cambio, una regulación "pro derechos" significaría, simple y llanamente, la aplicación en bloque de la legislación laboral y de Seguridad Social, que no sólo comporta la atribución de derechos laborales, profesionales y de la personalidad, individuales y colectivos -asociacionismo y acción colectiva-, de protección social y asistencia sanitaria, y de tutela judicial específica, sino que -como ocurre en otros muchos casos- garantizaría de manera simultánea protección de esas personas frente a los abusos y la explotación.

\section{La situación, a grandes rasgos, en el ordenamiento español}

En primer lugar, España se sitúa en un contexto internacional donde se adopta la perspectiva víctimocéntrica. Y en el marco de un ordenamiento constitucional en el que priman los valores rela- 
cionados con los derechos de la persona, pero en equilibrio con otros principios como los que garantizan las libertades económicas y de empresa, también especialmente preservadas por el Derecho de la UE, como ya se ha comprobado. Por otro lado, el Derecho Penal criminaliza la explotación de personas (trata, inmigración ilegal, menores de edad...), y la actividad de proxenetismo cuando medie violencia, intimidación, engaño o abuso de superioridad o de necesidad. Además, la normativa autonómica se ocupa de regular el uso de los espacios públicos para preservarlos de ruidos y otras molestias y riesgos para los ciudadanos (con no poca hipocresía y bastante falta de solidaridad, en relación con el ejercicio de la prostitución). Y, por fin, conforme al Derecho de obligaciones y contratos se exige para la validez de estos últimos -también los de prestación de servicios- la licitud del objeto y de la causa y la validez del consentimiento (libertad y ausencia de vicios).

En este fragmentario y contradictorio escenario se encuentra el Derecho del Trabajo, que no contempla ni explícita ni indirectamente las ocupaciones que se desenvuelven en el que podría denominarse "mercado de los servicios sexuales", si bien en el mismo sí operan y desarrollan sus negocios empresas y lobbies económicos que, bajo epígrafes de actividades económicas diversas (espectáculos, ocio, hostelería y restauración, fundamentalmente), explotan de manera no siempre encubierta la prostitución.

A partir de ahí, hay ciertos interrogantes para los que, al menos yo, no tengo una respuestas única y tajante. A saber, ¿es consustancial a la prostitución el tráfico de personas? ¿No es concebible la prostitución ejercida de manera voluntaria y libre? ¿La necesidad económica equivale a explotación? ¿No hay otras situaciones laborales donde también se produce? Desde este concreto punto de vista, sin perjuicio de la necesidad urgente de encontrar cauces alternativos de inclusión socio-económica para todas las personas, lo cierto es que convendría diferenciar, en un plano estrictamente jurídico, las situaciones de explotación y trata, de las de necesidad económica, que no excluyen per se la posible "normalización", regularización o legalización-limitativa y protectora- de la actividad. Una última pregunta gira en torno a si son todos los trabajos socialmente valiosos, y sólo la prostitución es intrínsecamente antisocial. Sin que se pretenda establecer parangón entre unas y otras actividades, podríamos pensar en el grado de reprobación o reproche que nos debería merecer o merece la existencia de empresas multinacionales dedicadas a la producción y venta de tabaco, alcohol u otras drogas legales como los opiáceos, que en países como los EEUU son causantes de un mayor número de muertes por sobredosis que las que se deben al VIH, los accidentes de tráfico o las armas de fuego, 72.000 muertes en 2017 [https://www.abc.es/sociedad/abci-opiaceos-epidemia-mas-letal-estados-unidos-201808162028_noticia.html; y https:/www.infobae.com/america/ eeuu/2018/08/16/epidemia-de-drogas-en-eeuu-un-record-de-72-000-muertes-por-sobredosisen-2017/ (ambos consultados el 6 de mayo de 2019)]; o empresas dedicadas a explotar actividades como el juego, o a la fabricación y venta de armamento; o, por poner un último ejemplo, industrias altamente contaminantes.

\section{El reconocimiento de la actividad asociativa de empresarios y trabajadores del sexo}

Antes de nada, merece la pena poner de relieve uno de los primeros síntomas de la tendencia a la regularización de facto de la prostitución ejercida libremente, en su caso, bajo la cobertura del alterne, que fue la aceptación de la creación y registro de asociaciones, tanto desde la esfera empresarial como del propio colectivo. En 2001 de la Asociación Nacional de Empresarios de Locales de Alterne (ANELA), aunque el episodio más llamativo y comentado se produce en 2003, con la creación de la Asociación Nacional de Empresarios "Mesalina", cuyo objetivo era defender y promocionar los intereses económicos y sociales propios del sector empresarial dedicado a la actividad mercantil de 
"tenencia o gestión, o ambas, de establecimientos públicos hosteleros destinados a dispensar productos o servicios que tengan como público objetivo terceras personas, ajenas al establecimiento, que ejerzan el alterne y la prostitución por cuenta propia”. La asociación nacía, pues, con el propósito de aglutinar a empresarios de establecimientos donde se ejercían el alterne y la prostitución en régimen de trabajo o actividad autónoma.

La Dirección General de Trabajo denegó la inscripción por dos motivos, la falta de regulación de la prostitución por cuenta propia y la denominación de la asociación patronal, que podía ser discriminatoria por razón de género. Impugnada la resolución administrativa denegatoria del registro, la sentencia dictada en la instancia (SAN de 23 de diciembre de 2003) estimó la pretensión de la asociación, entendiendo que la actividad de alterne era una actividad económica susceptible de tutela o reconocimiento en virtud del principio constitucional de libertad de empresa. La sentencia contribuye a distinguir la prostitución del alterne en virtud de la existencia de contacto físico, y de consentimiento o libertad, acuñando la llamada "doctrina de los niveles o pisos": legalidad del primer piso, el alterne; ilicitud del segundo piso, la prostitución. Este trascendental pronunciamiento fue confirmado por la STS de 27 de noviembre de 2004 (Rec.18/2004), que añade básicamente dos argumentos: el primero, que se trata de establecimientos hosteleros que precisan además de otro tipo de personal, como el de bar o limpieza; y el segundo, que no cabe presumir que tengan por finalidad explotar la prostitución, pese a que se admite la dificultad de separarla de ambas actividades.

Por su parte, las trabajadoras del sexo empezaron a organizarse, bien a través de cooperativas (Cooperativa de trabajo asociado para la prestación de servicios sexuales, Ibiza, 2014), bien a través de movimientos como el Colectivo Hetaira o la asociación APROSEX. Aunque el episodio reciente que más revuelo y polémica ha causado -y que aún está pendiente de resolución por el Tribunal Supremo- es el seguramente bien conocido a que dio lugar la constitución del sindicato OTRAS [Resolución de la DGT del Ministerio de Trabajo, Migraciones y Seguridad Social, de 31 de julio de 2018 (BOE 4 de agosto)]. Nacido con el propósito de desarrollar sus actividades "en el ámbito funcional del trabajo sexual en todas sus vertientes". La reacción de los colectivos feministas y la propia respuesta del Gobierno -que, a la sazón, se autoproclamaba también militante ferviente del feminismo- motivan una dimisión y la impugnación de los estatutos del sindicato, que es la que se encuentra pendiente de sentencia que resuelva el recurso de casación contra la sentencia estimatoria de la inicial demanda.

Desde mi punto de vista -visión que comparte una significativa parte de la doctrina laboralista (Ma I. BENAVENTE TORRES; y M. MINARRO YANINI)-, el caso ha sido objeto de un erróneo enfoque, por dos motivos. El primero tiene que ver con el sentido y alcance atribuido al trámite de depósito y registro de los estatutos sindicales, que en modo alguno puede convertirse en un filtro o injerencia gubernamental en el ejercicio de la libertad y autonomía sindicales que reconoce con carácter de derecho fundamental el art.28.1 CE. Si las fundadoras de OTRAS se identificaron como trabajadoras del sexo, en sus más variadas vertientes, con seguridad no correspondía a la Autoridad Laboral -mucho menos al Gobierno- pronunciarse sobre si ello amparaba una actividad lícita o lo contrario, competencia que corresponde únicamente a los jueces. El segundo motivo de discrepancia gira precisamente en torno a esta otra vertiente del asunto, la relativa al resultado de la impugnación de los estatutos de OTRAS contenido en la SAN nº174/2018, de 19 de noviembre de 2018 (Proced.258/2018), que en síntesis considera que no puede legalizarse un sindicato que ampara o agrupa a quienes desarrollan una actividad que, como la prostitución, no puede ser objeto de un contrato de trabajo válido. Comparto lo que con buen criterio se ha dicho a este respecto (M. MINARRO YANINI), y es que la AN confunde dos planos de análisis diversos, el de la titularidad del derecho de libertad sindical, y el de la legalización de la prostitución; el primero de los cuales, además, cuenta ya con un relevante precedente referido a la posible afiliación de los extranjeros sin 
permiso de trabajo -cuyo contrato también carecería de validez, aunque no de efectos-, cuestión que ya fue resuelta por el TC en una serie de sentencias (SSTC 236, 259, 263, 261, 262, 264 y 265/2007) en las que esencialmente se propugnaba un entendimiento material del concepto de "trabajador" a efectos de la libertad sindical, conforme al cual es titular del derecho fundamental quien de factor trabaja. La solución otorgada por la AN contraviene esa doctrina al haber adoptado una concepción eminentemente formalista de trabajador (M. MIÑARRO YANINI).

\section{El decisivo papel de la Inspección de Trabajo y Seguridad Social y de los tribunales para aflorar el trabajo sexual}

Casi todo lo que los estudiosos del Derecho del Trabajo conocemos del tratamiento de las actividades económicas relacionadas con el intercambio de sexo por dinero proviene de las resoluciones de los tribunales del orden social, la mayor parte de las cuales tienen a su vez origen en procedimientos de oficio incoados a partir de actuaciones de la Inspección de Trabajo en locales de alterne o similares. Actuaciones dirigidas a la comprobación de la existencia de incumplimiento de obligaciones empresariales en materia de empleo, trabajo de extranjeros, y afiliaciones, altas y bajas, y cotización a la Seguridad Social [todo ello con fundamento en lo dispuesto en la Ley 23/2015, de 21 de julio, Ordenadora del Sistema de Inspección de Trabajo y Seguridad Social, en la Ley sobre Infracciones y Sanciones del Orden Social (Texto Refundido aprobado por RD Legislativo 5/2000, de 4 de agosto), y en la $L O$ 4/2000, de 11 de enero, sobre derechos y libertades de los extranjeros en España y su integración social].

Por otra parte, al inicial problema relativo al difícil abordaje de la prostitución como actividad enmascarada bajo el alterne se ha venido a sumar el relativo al derivado del cierre de numerosos locales, que ha dado lugar a que la mayor parte de la actividad se desplace a pisos o viviendas particulares, a los que la Inspección de Trabajo no puede acceder sin la correspondiente autorización del juzgado contencioso-administrativo. Y sobre la concesión de estas parece que existe una práctica dispar y no un criterio uniforme.

El repaso de la jurisprudencia y, en mayor medida, de la doctrina de los tribunales de inferior grado que, tras la intervención de la Inspección, se han enfrentado al problema arroja las siguientes conclusiones. Por de pronto, la tesis de la Sala de lo Social del TS, que se conforma a lo largo de la década de los años 80 , es que la relación de las "señoritas de alterne" con los clubes o establecimientos donde realizan dicha actividad es de naturaleza laboral. Por cierto, el alterne generalmente se describe como la permanencia en el local, en horas fijas cada día, con una indumentaria sexy, para la captación de clientes varones a los que se incita al consumo de bebidas alcohólicas, a cambio de la percepción de una cantidad por día y/o un porcentaje del precio de las consumiciones que ellas hayan promovido [SSTS, 3 de marzo de 1981 (ECLI: ES:TS:1981:2517); y de 4 de febrero de 1988 (ECLI: ES:TS:1988:613), que a su vez remite a la doctrina ya sentada en aquella de 3 de marzo de 1981, y en las de 25 de febrero de 1984 y 14 de mayo de 1985].

Y este estado de cosas no se ha alterado, como prueban algunos pronunciamientos más recientes, como la STS de 21 de diciembre de 2016 (Rec.1868/15), que desestima el recurso por falta del requisito de la contradicción entre sentencias, dejando firme la sentencia de suplicación impugnada, en la que se reafirma el carácter asalariado en ese caso del alterne (el propietario del local fija horarios, las trabajadoras disfrutaban de un día de descanso semanal, y percibían en concepto de remuneración una cantidad del importe de la consumición del cliente, variable en función de si se trataba de bebida alcohólica o sin alcohol). Es importante subrayar que la falta del presupuesto de la identidad entre los supuestos de ambas sentencias - la recurrida y la de contraste- se cifra, justamente, en que esta última versaba sobre un caso de prostitución, inservible como término de 
comparación al considerarse una actividad no susceptible de constituir trabajo asalariado, a diferencia del alterne.

En esta misma línea se pueden encontrar otras resoluciones, la mayor parte en forma de auto inadmitiendo el recurso de casación unificadora [por todos, puede verse el Auto de la Sala de lo Social del TS de 21 de noviembre de 2017 (Rec.859/17)]; en las que, al mismo tiempo, se distingue entre el alterne en régimen de dependencia -de naturaleza laboral, por consiguiente-, del que se desarrolla con carácter autónomo [por ejemplo, en el Auto de la Sala de lo Social del TS de 11 de abril de 2013 (Rec.2743/12), en el que la sentencia de contraste basa la existencia de independencia en el hecho de que las chicas entraban y salían del local cuando querían ellas, y cobraban del cliente la cantidad estipulada -20 euros por consumición- directamente].

Entre los numerosos pronunciamientos de órganos jurisdiccionales del orden social de grado inferior merecen especial consideración dos sentencias del Juzgado de lo Social $\mathrm{n}^{\mathrm{o}} 1$ de Mataró; la primera, la de 23 de julio de 2007 (Autos 247/07), dictada en procedimiento de despido, que se declara improcedente, empieza por calificar como laboral la relación de la encargada de un prostíbulo ubicado en un piso del que la parte demandada era arrendataria. Las encargadas eran seleccionadas a partir de anuncios de prensa; consistiendo su tarea en abrir la puerta a los clientes, a los que se ofrecía una bebida de cortesía, se les presentaba a las mujeres; para luego tomar nota de los servicios sexuales prestados, y del precio abonado por el cliente, del que detraía la parte correspondiente a la titular del establecimiento, que se apuntaba en una libreta e ingresaba en una caja fuerte. En el piso trabajaban tres encargadas, que hacían turnos de doce horas; percibiendo 60 euros por día, que se les abonaban a fin de mes en función del total de días trabajados. El local funcionaba las 24 horas del día, y las mujeres que en él prestaban sus servicios sexuales ocupaban las habitaciones el día entero, incluso para dormir allí. A partir de una denuncia de una extranjera en situación irregular que trabajaba en otro local de la misma titular, el piso fue clausurado. Pese a lo cual, la empleadora procedió a abrir otro en distinta localidad, donde ofreció a la demandante proseguir con su actividad. A los siete días de hacerlo, la actora fue verbalmente despedida.

Ese mismo Juzgado de Mataró dictó poco después otra sentencia de fecha 5 de octubre de 2007 (Autos 246/07), en procedimiento de reclamación de cantidad promovido por las otras dos encargadas del piso del caso anterior. La pretensión es estimada en parte sobre la base de la declaración de la existencia de relación laboral, con idénticos razonamientos que en la sentencia previa; aunque se desestima en la parte referida a la aplicación de las cuantías salariales estipuladas en el Convenio colectivo de hostelería de Cataluña. Sobre este punto — razona el magistrado- pese a que a estos pisos se les catalogue como "pensiones", no puede considerarse que la actividad que en ellos en verdad tiene lugar - la prostitución - pueda quedar comprendida en el ámbito funcional del convenio sectorial de referencia. Esta sentencia fue confirmada por la STJS Cataluña, de 24 de abril de 2009 (Rc.900/08). En definitiva, ello muestra que, aun de un modo indirecto o contextual, los tribunales se vienen ocupando del negocio de la prostitución como nicho de trabajo. Mi pregunta aquí sería ¿Por qué si se atienden las reclamaciones de las encargadas de un prostíbulo, y se niega todo derecho a las prostitutas? ¿No merecería la misma reprobación social cualquier actividad que gire en torno a ese negocio aunque no consista en la práctica del sexo?

Dos recientes pronunciamientos del TSJ de Madrid abundan en el carácter laboral de la actividad de alterne, y añaden alguna consideración de interés más. La STJS de Madrid de 2 de febrero de 2018 (Rec.1015/17) [ECLI:ES:TSJM:2018:948], que destaca que se trata de una actividad que genera unos rendimientos económicos que deben estar sometidos a condiciones tributarias y laborales que protejan a los trabajadores; y la STJS de Madrid de 4 de febrero de 2019 (Rec.1276/18), que también señala, junto a los habituales indicios de laboralidad, que la empresa obtiene un lucro constatado. 


\section{Algunos pronunciamientos recientes que tal vez apunten a un cambio de paradigma en el enjuiciamiento de estos casos}

El primero de ellos es la Sentencia del Juzgado de lo Social no 10 de Barcelona, de 18 de febrero de 2015 (Autos 835/13), cuyo autor, además, ha expuesto con más detalle su tesis y sus argumentos (J. AGUSTÍ MARAGALL). De nuevo se trata de un procedimiento de oficio instado esta vez por la TGSS, a partir de la comunicación remitida por la Inspección de Trabajo. Esta última, en el transcurso de una visita a un centro de masajes eróticos en compañía del grupo especializado de la Policía Nacional, levantó acta de infracción por falta de afiliación y alta de las personas que allí trabajaban. Agotadas las diligencias informativas incoadas por la Policía, el procedimiento de oficio prosiguió, dando lugar a esta sentencia, cuyo relato fáctico recoge los siguientes hechos: las personas que se encuentran en el local manifiestan dedicarse a dar masajes, actividad que efectivamente es la que consta en la licencia de actividad expedida por la autoridad municipal ("centro de masajes"); la empresa, citada por la Inspección, como viene siendo habitual declara que esas personas ejercen la prostitución por cuenta propia, limitándose la entidad propietaria del local a alquilarles las habitaciones. Consta, sin embargo, que dichas personas debían comparecer en el local en los horarios convenidos (de 12:00 a 20:00 h.), y quedar a la espera de la llegada de clientes, quienes las elegían para los servicios sexuales requeridos, cuyo precio y previo pago (incluso mediante tarjeta de crédito) concertaban los clientes con la encargada. Al final de la jornada esta última entregaba a cada una de las trabajadoras la parte convenida respecto a cada uno de los servicios prestados. La captación de los clientes se llevaba a cabo a través de una página web, en la que explícitamente se ofertaban servicios sexuales. El material necesario y el mantenimiento de las instalaciones eran por cuenta de la empresaria demandada.

El debate jurídico gira estrictamente en torno a si existía una relación de trabajo asalariado o por cuenta propia. Y el juzgador, pese a que afirma no desconocer la jurisprudencia tradicional sobre la ilicitud del objeto y de la causa del contrato de trabajo, y sobre la incompatibilidad del proxenetismo y la prostitución con los derechos humanos básicos, llega a la conclusión de que concurren efectivamente los rasgos esenciales de un contrato de trabajo. Para salvar el primero de esos escollos el magistrado invoca la doctrina contenida en la STS, Sala de lo Penal, 425/2009, de 14 de abril, según la cual, “...la cuestión de la prostitución voluntaria... no puede solventarse con enfoques morales o concepciones ético-sociológicas ya que afecta a aspectos de la voluntad que no pueden ser coartados por el derecho...". Y, en la misma línea, con cita de la STS 651/2006, de 5 de junio, considera que sólo cabría hablar del delito de "explotación laboral" o "explotación sexual lucrativa" cuando se detectaran condiciones abusivas de trabajo o "grave riesgo para los derechos" (STS 152/2008, de 8 de abril). Únicamente estaría, pues, penalmente prohibido el proxenetismo en el marco de la prostitución forzada, sin consentimiento de la persona que pudiera ser expresivo de su libertad sexual. Circunstancia que concurriría tanto si la voluntad se obtiene mediante el empleo de violencia, intimidación o engaño, abuso de superioridad o de situación de necesidad o vulnerabilidad; como cuando se trate de "explotación laboral" por concurrir condiciones abusivas de trabajo. Ninguna de las cuales se aprecia en el caso, a la vista de lo decidido por el Juzgado de Instrucción no 2 de Barcelona que había acordado el sobreseimiento y posterior archivo de las diligencias previas incoadas. Decisión que proyecta efectos sobre el pleito laboral.

El segundo obstáculo se encuentra, a juicio del Magistrado, en una doctrina que viene afirmando que toda relación de prostitución, intrínsecamente, es contraria a la dignidad de la persona y a los derechos que le son inherentes (art. $10 \mathrm{CE}$ ), y que contraviene derechos fundamentales como la libertad, la igualdad y la integridad física y moral (la referencia al derecho al honor ya prácticamente no se invoca, como derecho lesionado). Frente a ello el juzgador se formula las siguientes 
preguntas: si es posible admitir que un contrato libremente pactado despoje a una de las partes de su condición de persona; el porqué de entender que la venta de servicios sexuales atenta contra la dignidad de quien lo ha decidido libremente; y si hay algo más indigno y degradante que no ser reconocido como sujeto capaz de adoptar decisiones libres. Son términos prácticamente literales de la sentencia. En opinión del juez -que comparto-, bajo una política del derecho -no desde un posicionamiento meramente ideológico- resulta imposible seguir manteniendo que la capacidad de autodeterminación personal en el ámbito sexual dependa de una noción de dignidad selectiva, que pueda ser negada en el caso de la prostitución. Entre otras razones, porque no parece una lectura compatible con la jurisprudencia constitucional, que ofrece una vertiente positiva de la idea de dignidad -como correlato de la libertad- en igualdad para todos. En concreto, con cita de la STC 192/2003, de 27 de octubre, se señala que: “... la dignidad personal del trabajador debe ser entendida como el derecho de todas las personas a un trato que no contradiga su condición de ser racional, igual y libre, capaz de determinar su conducta en relación consigo mismo y su entorno, esto es, la capacidad de autodeterminación consciente y responsable de la propia vida”.

Resulta inaceptable, concluye, que esta teoría general pueda ser olvidada en relación con una actividad laboral concreta, como la del trabajo sexual. Y añade que "...la valoración como indigna de la actividad de la prostitución responde a una valoración de tipo moral, que no puede imponerse al libre arbitrio individual, y que solamente sería predicable de las condiciones en las que se ejerce, lo cual quedaría reparado con la regulación y tutela de su ejercicio por parte de la normativa laboral, al contribuir a su inclusión social, coadyuvando a restituirles la dignidad que tradicional e injustificadamente se les ha negado."

Y respecto del enfoque de género que proporciona el Derecho de la UE, con referencia expresa y detallada a la ya citada Resolución del Parlamento Europeo de 24 de febrero de 2014, lejos de considerarlo un argumento contrario a una posible laboralización de la actividad de prostitución voluntaria, lo esgrime precisamente como razón para otorgar a las trabajadoras la correspondiente protección. Considera el magistrado que lo contrario haría más precaria la situación de estas mujeres, cuando en cambio el Estado está ofreciendo cobertura legal al proxenetismo, vía reglamentación administrativa y despenalización aplicativa.

Antes de concluir estas páginas merece detenerse en un asunto del máximo interés, el conocido como "caso Evelyn". De las varias acciones judiciales emprendidas por esta tenaz mujer la base de datos del Cendoj sólo recoge la resuelta por STSJ de Madrid, Sala de lo Social, de 18 de febrero de 2019 (Rec.868/18) [ECLI: ES:TSJM:2019:11244], donde, a propósito de una demanda de tutela de derechos fundamentales, lo que se dirime es la competencia del orden social de la jurisdicción sobre la base de considerar la existencia de una relación laboral entre la demandante y la empresa titular del club de alterne en el que aquella presta sus servicios.

No obstante, a través de algunos medios de comunicación [https:/elpais.com/ccaa/2019/12/04/ madrid/1575486646_675126.html; https:/www.elespanol.com/reportajes/20190227/evelyn-prostituta-rebelde-historica-victoria-burdel-madrid/379463286_0.html (última consulta, 27 de abril de 2020)] y de otras fuentes de información y análisis (E. ROJO TORRECILLA) conocemos la existencia de otro pronunciamiento de la misma fecha, esta vez recaído en procedimiento de despido, donde se ofrece un relato de la realidad que la propia Evelyn y otras mujeres vivían en uno de los "mayores burdeles de Madrid" (como reza uno de los titulares de prensa de referencia). El grupo titular del club de alterne-Grupo Empresarial La Florida- disponía junto al Club de alterne Flower's de un edificio de apartamentos - ApartaHotel La Florida- donde las trabajadoras vivían, además de, en algunos casos, ejercer la prostitución; y donde la protagonista de este relato llegó a atrincherarse para protestar por su situación, una vez que la empresa la "despidió" y le ordenó desalojar la habitación que ocupaba. A raíz de estos hechos, la Inspección de Trabajo procedió a activar una actuación que quedó paralizada a 
la espera de que el Tribunal Supremo se pronunciase finalmente sobre la naturaleza de la relación. La empresa, además, había dejado en 2007 de abonarles las comisiones con el fin de crear la apariencia de inexistencia de relaciones laborales con las alternadoras.

La Sala de lo Social del TSJ de Madrid considera, en cambio, que los servicios de alterne se realizan en un local de negocio, en el horario fijado por la empresa y bajo sus instrucciones (que incluían la prohibición de subir bebidas a las habitaciones por motivos de seguridad), por lo que concurre la nota de dependencia característica de la relación laboral; y va más allá, al sostener que la supresión de las comisiones constituye una novación nula por comportar una renuncia de derechos, y que admitir un trabajo sin retribución sería tanto como admitir la esclavitud (E. ROJO TORRECILLA). La Sala estima las pretensiones de la defensa de Evelyn, declara la existencia de relación laboral cuando la prostitución se ejerce en el mismo local del alterne, y condena a la empresa, calculando las retribuciones conforme a las que fija el Convenio colectivo de Hostelería y Hospedaje de la Comunidad de Madrid. No dejan de tener interés las declaraciones de la empresa cuando anuncia que recurrirá esta sentencia y sostiene que ellas ejercen libremente la prostitución y que en algunos casos ello les puede reportar ganancias de hasta 13.000 euros netos al mes, por lo que las afirmaciones de la sentencia constituyen una "falta de respeto hacia la gente que de verdad está esclavizada". Evely, por su parte, afirma que llegará hasta el final, "por dignidad, por respeto hacia las mujeres y hacia (su) profesión". "Soy prostituta... trabajadora y persona [proclama]... "por esto tengo mis derechos, los reivindico y los defiendo".

\section{A modo de conclusión}

Sin duda es comprensible que cuanto toca o atañe a la "industria del sexo" resulte en sí mismo ominoso y reprobable en un plano estrictamente individual. Pero quizá esto no sea suficiente argumento para rechazar de plano una discusión teórica sobre qué y cómo habría que regular las diversas formas en que aquella se despliega. Existen otros muchos negocios y "trabajos" que, pese a lo oprobioso que puedan resultar, ellos mismos o las condiciones en que se desarrollan, para quienes los desempeñan o incluso para el resto de la sociedad, no levantan ni la mitad de la polémica ni causan una irritación o indignación comparables a las que despierta la prostitución. Y existen colectivos de mujeres trabajadoras que comprometen su vida y su cuerpo al límite de su propia libertad y salud, en situaciones de explotación, vulnerabilidad y pobreza laboriosa, que en cambio son perfectamente legales. Léase, trabajo doméstico, el de las camareras de pisos, u otros similares. ¡Ojalá todo trabajo fuera capaz de dignificar a las personas y garantizar su libertad!

Por otro lado, las tesis de un signo y su contrario sobre si hay que regular o proscribir la prostitución no dejan de ser manifestaciones del "rearme ideológico" proveniente del conservadurismo -en ocasionen identificado como "patriarcado"- o reactivamente del feminismo radical (F. ALEMÁN PÁEZ), rearme dicotómico del que aquí se ha procurado escapar. Creo sincera y honestamente que los problemas y dilemas que plantea la prostitución no se resuelven ni ahondando en la represión del fenómeno en todas sus vertientes o formas, ni legalizando la prostitución aun con límites, cautelas y garantías (en Alemania los empresarios protestan porque les "cargan" con las obligaciones naturales de un empresario, y las trabajadores porque la posición de sometimiento a "directrices" y órdenes de un empresario pueden comportar situaciones indeseables en relación con la forma de realizar su actividad). Pero también pienso que la laboralización de la prostitución tendría algunos efectos benéficos, empezando por la protección jurídica de las personas que la ejercen, cuya desprotección y vulnerabilidad se ha puesto muy crudamente de manifiesto en estos momentos de crisis sanitaria y social [https://vitrage.blogs.uv.es/2020/04/01/el-impacto-del-covid- 
19-en-las-y-los-trabajadoras-sexuales-fernando-fita-ortega-profesor-titular-derecho-de-trabajo-yde-la-seguridad-social/]; y terminando por el no menos relevante aporte a las arcas públicas vía recaudación fiscal y de cotizaciones al sistema de Seguridad Social.

Creo, en fin, que el óbice consistente en las manifestaciones de la subordinación que toda relación laboral conlleva, como en otros muchos casos, se encontraría contrarrestado por el necesario respeto a la dignidad humana, la libertad sexual y el resto de derechos fundamentales y básicos de toda persona. Esto no es nada nuevo para el Derecho del Trabajo. Recuerdo ahora, para terminar, un caso que comentaba hace unos años un querido y admirado maestro, cuando relataba cómo una mujer que trabajaba en un club de alterna practicando la prostitución murió en un accidente de automóvil regresando a su casa de madrugada en un coche conducido por el dueño del local, dejando a sus dos hijos sin pensión de orfandad porque la prostitución no era, ni es, una actividad protegida por el sistema de Seguridad Social (A. DESDENTADO BONETE). Y no puedo dejar de conmoverme.

\section{Bibliografía citada}

J. AGUSTÍ MARAGALL, "Razones para la laboralización de la libre prestación de servicios de prostitución por cuenta ajena”, IUSLabor 1/2015 [https://www.raco.cat/index.php/IUSLabor/article/download/290966/379315 (consultado el 4 de mayo de 2019)]

F. ALEMÁN PÁEZ, "El trabajo sexual en la Ley alemana reguladora de la prostitución ("das prostituiertenschutzgesetz"). Bases teóricas y exegéticas de una isonomía crítica", Derecho de las Relaciones Laborales no7, julio 2018, pp.734 y ss.

$M^{a}$ I. BENAVENTE TORRES, "Depósito de los estatutos del sindicato y límites al poder de control de la Administración”, Revista Trabajo y Seguridad Social, CEF, num.418, 2018, pp.95 y ss.

A. DESDENTADO BONETE, "Contrato de trabajo y prostitución. Una reflexión sobre la sentencia de la Sala 2a del Tribunal Supremo de 14 de abril de 2009”, La Ley no7238, 2009

J.F. LOUSADA AROCHENA, "El tratamiento legal dela prostitución: ¿ Forma de esclavitud o trabajo sexual?”, en El derecho antes las formas contemporáneas de esclavitud, E. PÉREZ ALONSO y otros (dir.), Tirant lo Blanch, Valencia, 2017, pp.632 y ss.

M. MINARRO YANINI, "La libertad sindical de "todos" no alcanza a "las OTRAS": la Audiencia Nacional confunde titularidad del derecho de libertad sindical con legalización de la prostitución”, Revista Trabajo y Seguridad Social CEF no430, enero 2019, pp.143 y ss.

S. OLARTE ENCABO, "La prostitución voluntaria ¿Una forma de esclavitud o de ejercicio de libertad personal, de trabajo y de empresa?", en El derecho antes las formas contemporáneas de esclavitud, E. PÉREZ ALONSO y otros (dir.), Tirant lo Blanch, Valencia, 2017, pp.517 y ss.

GLORIA POYATOS, "Las mentiras, las grandes mentiras y las estadísticas sobre prostitución" [https://elestantedelaciti.wordpress.com/2017/10/20/las-mentiras-las-grandes-mentiras-ylas-estadisticas-sobre-prostitucion/ (publicado el 20 de octubre de 2017, consultado el 7 de abril de 2018)]

P. RIVAS VALLEJO, "Aspectos laborales de la prostitución voluntaria: perspectiva comunitaria y modelos comparados", en El derecho antes las formas contemporáneas de esclavitud, E. PÉREZ ALONSO y otros (dir.), Tirant lo Blanch, Valencia, 2017, pp.569 y ss.

E. ROJO TORRECILLA, "A vueltas con el alterne y la prostitución, y sus borrosas fronteras sobre la laboralidad de la relación. Una nota a propósito de la sentencia del TSJ de Madrid de 18 de febrero de 2019”, en el blog El nuevo y cambiante mundo del trabajo. Una mirada abierta y critica a las nuevas realidades laborales [https://bit.ly/2OjxdoQ (22 de marzo de 2019, última consulta el 29 de abril de 2019)] 
C.VILLACAMPA ESTIARTE, "La nueva directiva europea relativa a la prevención y la lucha contra la trata de seres humanos y a la protección de las víctimas ¿Cambio de rumbo de la política de la Unión en materia de trata de seres humanos?", Revista Electrónica de Ciencia Penal y Criminología RECPC 13-14 (2011) (http://criminet.ugr.es/recpc/13/recpc13-14.pdf) 